\title{
THEODOR ADORNO: FILOSOFIA DE CONTEÚDOS E MODELOS CRÍTICOS
}

Ricardo MUSSE ${ }^{1}$

- RESUMO: Procura-se destacar aqui, a partir da relação de mútua dependência entre o concreto e o especulativo em Theodor Adorno, algumas características próprias de sua exposição filosófica. A recusa de definições, a busca de constelações, a construção de "modelos críticos" tornam-se mais inteligíveis quando examinadas à luz da relação entre os conceitos e o não-conceitual. Pretende-se assim esclarecer melhor a relação entre verdade e história no pensamento de Adorno.

- PALAVRAS-CHAVE: Theodor Adorno, teoria crítica, marxismo.

\section{Especulativo e concreto}

Adorno autocompreende sua teoria como um "pensamento de conteúdos". Com isso, procura indicar que a teoria deve mergulhar no heterogêneo, sem a segurança de categorias prévias, prescindindo da técnica usual que aplica os conceitos àquilo que já estava de antemão subsumido em sua definição.

Trata-se sobretudo de uma recusa a degradar os conteúdos à condição de exemplos de categorias, patente na tentativa de evitar o estabelecimento de um "corpus" de teoremas, de uma fórmula à qual os fenômenos sejam reduzidos. Esse esforço visando à concreção complementa-se, num deslocamento, com a alteração do objeto de interesse da teoria: revolta-se "contra a doutrina, arraigada desde Platão, segundo a qual o mutável, o efêmero,

1 Doutor em filosofia e professor no departamento de sociologia da USP. Artigo recebido em 07/2009 e aprovado em 12/2009. 
não seria digno da filosofia; revolta-se contra essa antiga injustiça cometida contra o transitório, pela qual ele é mais uma vez condenado, no plano do conceito" (Adorno, 1986, p. 174).

A valorização do singular como insubmisso a categorias, distinta de um mero ajuntamento de dados, demanda uma ampliação, um alargamento do âmbito da experiência filosófica. Exige, nos termos de Adorno, "ir além da separação oficial entre filosofia pura e aquilo que tem conteúdo objetivo (Sachhaltigem) ou é formalmente científico" (Adorno, 1982, p. 10).

O "momento especulativo", por sua vez, também é reafirmado como essencial. Recorrendo a uma frase de Walter Benjamin, Adorno, no prefácio a Dialética Negativa, apresenta o livro e, por conseguinte, a pretensão de estabelecer uma teoria que libere a dialética de sua essência afirmativa, como um trajeto pelos "desertos gelados da abstração".

Mas não se trata de preservar as modalidades corriqueiras de "especulação". Adorno procura fundamentar a distinção entre sua concepção e as acepções tradicionais de especulativo a partir do próprio ato de pensar: "[...] pensar já é em si, antes de qualquer conteúdo particular, negação, resistência (Resistenz) contra aquilo que lhe é impingido" (Adorno, 1982, p. 30).

O conceito adorniano de "especulativo" não configura mera metodologia de trabalhos aplicados, mas resistência, negatividade, crítica ao estabelecido:

Em tal resistência (Widerstand) sobrevive o momento especulativo: como aquilo que não deixa que sua lei seja prescrita pelos fatos dados (Tatsachen), transcendendo-os mesmo em contato mais estreito com os objetos e na recusa de uma transcendência sacrossanta. É onde o pensamento está para além daquilo ao qual, resistindo, ele se prende, que se encontra sua liberdade. (Adorno, 1982, p. 29)

A rebelião contra o imediato nutre a crítica de Adorno ao positivismo. Nesse ponto, ele aproxima-se da tradição idealista, com a qual compartilha a recusa à predominância do factual, dos dados imediatos. Rejeita, no entanto, também o modelo idealista, pois este, segundo ele, em seu apriorismo estático concebe harmonicamente a relação entre o lógico e o histórico, o teórico e o empírico. Acusa ainda a filosofia idealista de ater-se à exclusiva imanência de construções lógicas, identificando, em chave falsa, teoria e unidade formal, universal e particular.

Uma vez que a teoria "não pode, mesmo após recusar o idealismo, prescindir da especulação" (Adorno, 1982, p. 27), convém, para melhor desenvolvê-la, restabelecer o especulativo em um sentido mais amplo que aquele que possuía em Hegel. Este teria, segundo Adorno, positivado o especulativo ao vinculá-lo com o terceiro momento da dialética, o racional-positivo, privando-o daquilo que mais interessa, a negatividade, o potencial crítico. 
Avessos a uma possível unificação sistemática, tensos, retesados em uma relação de descontinuidade mediada pela conexão entre o universal e o particular em sua concreção histórica, os momentos especulativos e concretos não se inscrevem num mesmo continuum. Tampouco são momentos estanques, já que estão inter-relacionados: o pensamento especulativo necessita, em sua imanência, do corretivo do objeto, do confronto com o teor coisal; a filosofia concreta, por sua vez, não pode prescindir da negatividade do pensamento e mesmo do desdobramento do especulativo.

Nesse prisma, a abordagem da dialética em Adorno ultrapassa a forma de questionamento usual e predominante na vida acadêmica, que se limita a indagar pela validade atual de uma maneira de filosofar historicamente transmitida ou, então, se preocupa apenas em determinar o estatuto filosófico do objeto de conhecimento. Redimensionada como uma inquirição acerca da possibilidade de pensar uma dialética fora do registro de um sistema idealista, a "dialética negativa" vai além, ao transformar essa questão numa indagação da própria possibilidade de filosofar sobre conteúdos.

\section{Mediato e imediato}

O interesse da teoria desloca-se para o que até então parecera supérfluo - o individual, o particular, o não-conceitual -, mas os meios de reflexão, descartados a intuição e o imediato, ainda são única e exclusivamente conceitos. Com isso, o pensamento de Adorno instaura e move-se numa contradição autoconsciente, no dilema de expressar conceitualmente o não-conceitual. No núcleo dessa contradição, ele identifica a própria meta do conhecimento: "A utopia do conhecimento seria abrir o não-conceitual com conceitos, sem torná-lo igual a eles" (Adorno, 1982, p. 21). Junto com uma incessante contestação da soberania do conceito, Adorno promove uma revalorização do conceito como fator de conhecimento. Mas, como escapar da armadilha que identifica pensamento conceitual e idealismo?

Uma vez aceita como premissa a ressalva de que o instrumento da filosofia são os conceitos, não cabe - como fazem o materialismo vulgar e o existencialismo - rejeitar o percurso que parte dos conceitos. Permanece incólume, assim, o pressuposto que identifica toda forma de pensar apoiada em conceitos como idealismo. Segundo Adorno, o que todos reafirmam, mesmo que apenas implicitamente, e o que cabe negar com veemência é a auto-suficiência do conceito. Seria necessário recusar tanto a sua transformação em fetiche no idealismo como a vereda trilhada por essas frustadas tentativas de escapar ao conceitual, que apenas servem para reforçar sua pretensão à unidade e à onipotência. Para tanto, convém promover uma inversão na própria definição de conceito: "Em verdade, todos os conceitos, 
inclusive os filosóficos, visam ao não-conceitual, já que são momentos da realidade, que impõe a formação deles" (Adorno, 1982, p. 23).

A tradição filosófica já havia, desde Kant, se assegurado da necessidade de não prescindir do não conceitual, pelo menos associando-o ao conceito, para evitar a vacuidade deste último. Afinal, conceitos sempre remetem a algo, e na medida em que tentam significar algo além deles próprios, designam, enfaticamente, o não-conceitual. Para Adorno, no entanto, tais considerações ainda são insuficientes. É necessário dar outro passo, invertendo o sentido dessa relação:

Aquilo que caracteriza [o conceito] é tanto a relação ao não-conceitual - assim como, mesmo para a teoria do conhecimento tradicional toda definição de conceitos necessita de momentos não-conceituais, dêicticos - quanto, ao contrário, afastar-se do ôntico enquanto unidade abstrata dos onta compreendidos por ele. Mudar a orientação da conceptualidade, voltá-la para o não-idêntico, eis a charneira de uma dialética negativa. (Adorno, 1982, p. 24)

Com essa inversão, desdobrando uma nova formulação para o conceito, Adorno procura combater a "ilusão de uma subjetividade constitutiva" e contestar seu correlato necessário: a ideia de uma filosofia da identidade. Uma vez dissipada essa ilusão, a articulação conceitual não se organiza mais a partir de um princípio, tampouco pretende abarcar a integralidade da experiência, a totalidade do finito.

Recusando o propósito de instaurar um sistema, o pensamento de Adorno desenvolve-se por meio da tessitura de conexões anti-sistêmicas: "O ensaio exige mais que o procedimento por definições, a interação de seus conceitos no processo da experiência espiritual. Nesta, eles não constituem nenhuma continuidade operacional e o pensamento não avança unilateralmente, os momentos se entretecem como num tapete" (Adorno, 1986, p. 176-7). Avessa às modalidades de organização sistemática do saber, essa articulação é denominada por Adorno de "constelação".

A renúncia à afirmação predicativa conduz Adorno a atenuar a reivindicação de identidade. Para tanto, utiliza em larga escala figuras micrológicas vinculadas à estrutura da sentença e da frase numa construção em parataxe. Seus textos procuram esquivar à hierarquia lógica da sintaxe subordinativa (atada à função sintética do conceito). São recorrentes figurações hipotéticas audaciosas, parataxes assemelhadas a desordens artísticas, alinhamentos cujos elementos conectam-se de outro modo que as normas de ordenação de juízos. Tentando escapar da submissão da linguagem a um modelo prévio de pensamento, seu estilo aferra-se à "presença concreta da constelação das palavras, de uma constelação, todavia, que não se satisfaz com a forma da sentença. Esta, como unidade, nivela a multiplicidade que se encontra nas palavras" (Adorno, 1973, p. 102). 
Não se trata, porém, de nenhuma crença no poder mágico da palavra ou da escrita. A constelação só possibilita o conhecimento do objeto na medida em que instaura uma via de acesso ao processo social e histórico nele acumulado:

O objeto abre-se a uma insistência monadológica que é consciência da constelação na qual ele se encontra: a possibilidade de um mergulho no interno necessita daquilo que é externo. Mas, tal universalidade imanente do singular é objetiva apenas como história sedimentada. (Adorno, 1982, p. 165)

Para conhecer o singular, o individual, para efetivar-se como micrologia, o pensamento só dispõe daquilo que não é particular, ou seja, de conceitos; logo, de meios que são, por definição, macrológicos. Por outro lado, a imersão no singular tem como momento imprescindível a necessidade de "ir além do objeto", condição de possibilidade da exigência de superar o pensamento identificante. Essa maneira de pensar recebeu, em Adorno, um nome determinado - a tensão entre filosofia concreta e especulativa impõe que a reflexão efetive-se por intermédio de modelos críticos:

A exigência de rigor (Verbindlichkeit) sem sistema é a exigência de modelos de pensar. Estes não são meramente de tipo monadológico. O modelo atinge o específico e mais que o específico, sem volatizar-se no seu conceito superior mais geral. Pensar filosoficamente equivale a pensar em modelos; a dialética negativa é um conjunto de análises de modelos. (Adorno, 1982, p. 39)

Pontes entre as categorias qualitativamente modificadas da dialética negativa e o domínio do real, os modelos de Adorno ocupam um lugar privilegiado na conexão que ata o "especulativo" ao "pensamento de conteúdos". Uma vez que essa relação mútua deve configurar uma teoria da nãoidentidade (na qual o particular não seja mais suprimido pelo conceito), o trânsito de mão dupla entre concreto e especulativo adquire a forma de uma tensão, de uma diferenciação.

Compete ao "especulativo" combater a primazia do sujeito, a organização sistêmica do saber, o positivismo, o idealismo, em suma, a filosofia da identidade em seu sentido abrangente. Na prática cotidiana, o papel do especulativo - explicitado apenas retrospectivamente - não consiste em fundamentar, mas apenas em estabelecer justificações "a posteriori" para o exercício de análises concretas. Os trabalhos aplicados, por sua vez, tampouco se confundem com a explicitação indiferenciada de considerações gerais, já que não se trata de meros exemplos: seu procedimento discrepa da mera exemplificação.

De modo simplificado, pode-se dizer que modelos consistem em trabalhos aplicados nos quais a teorização fornecida pelo desenvolvimento do es- 
peculativo é explicitamente considerada. Para melhor compreender esse conceito, o mais adequado é debruçar novamente sobre suas singularidades.

\section{Sistematicidade e rigor}

Adorno reconhece que a crítica ao sistema não liquida sua pertinência. Aliás, adverte que, para evitar o ceticismo e conservar o vigor da teoria, cabe conservar a insistência sobre a possibilidade de conhecer própria do pensamento sistemático. Nesse sentido, sua posição não configura um simples descarte desse procedimento: "a crítica do sistema e o pensamento assistemático permanecerão exteriores enquanto não puderem liberar a força de coerência que os sistemas idealistas adscreveram ao sujeito transcendental" (Adorno, 1982, p. 36).

A rejeição do sistema caminha junto com a conservação desse seu impulso, ou, na terminologia de Adorno, com a manutenção da "sistematicidade". A exigência desta, por sua vez, pode ser entendida como uma busca de rigor: "uma filosofia especulativa, sem alicerce idealista, requer fidelidade ao rigor para quebrar a reivindicação autoritária de poder" (Adorno, 1982, p. 29).

"Rigor", em Adorno, não se encontra associado à lógica convencional, mas antes vinculado estritamente à expressão:

Expressão e rigor não são, para a filosofia, possibilidades dicotômicas. Elas necessitam uma da outra, uma não é sem a outra. A expressão é desembaraçada da sua contingência pelo pensar em relação ao qual a expressão esforça-se tanto quanto o pensar em relação a ela. O pensamento só torna-se denso (bündig) pelo expressado, através da exposição lingüística; o dito laxo está mal pensado. (Adorno, 1982, p. 29)

Desse modo, a exposição não é algo indiferente ou exterior à teoria, mas imanente a sua ideia:

O momento integral de expressão da filosofia, não-conceitual e mimético, é objetivado só através da exposição, da linguagem. A liberdade da filosofia nada mais é que a capacidade de proporcionar voz à sua não-liberdade. Quando o momento da expressão é arrogado degenera em visão de mundo; onde a filosofia renuncia ao momento da expressão e ao dever da exposição, é assimilada à ciência. (Adorno, 1982, p. 29)

A determinação do lugar da expressão no pensamento de Adorno permite compreender melhor tanto seu estilo quanto o caráter peculiar de seus escritos. A exposição paratática, a procura de constelações, a utilização incessante de tropos e quiasmos, a brusca associação de teor coisal e especulativo, bem como a preferência anti-sistêmica por artigos, aforismos, ver- 
betes, palestras, notas, estudos, pequenos escritos, ensaios e modelos; em suma, o caráter fragmentário de sua escrita e de seus textos devem ser considerados como um elementos dessa preocupação em suplantar o tom, o estilo e o modo de pensar sistêmico.

A ênfase na expressão tampouco pode ser dispensada na tarefa de delinear o lugar e o estatuto da filosofia, por meio da distinção que a diferencia seja da ciência seja da arte:

Ciência e arte se separaram, com a progressiva objetivação do mundo ao longo do processo de desmitologização; é impossível restabelecer, com um toque de mágica, uma consciência em que visão e conceito, imagem e signo, constituam uma unidade (se é que isso alguma vez chegou a ocorrer), e a restauração de tal consciência acabaria recaindo no caótico. (Adorno, 1986, p. 170-1)

Condena-se assim não apenas uma falsa reunificação, rejeita-se também a tendência a pensar essa distinção como absoluta: "não é porque arte e ciência se separaram na história que se há de hipostasiar sua antítese" (Adorno, 1986, p. 172).

A consciência da distinção entre exposição filosófica e científica conduz Adorno a abandonar o procedimento de expor a partir de definições. A exigência de definições em filosofia é considerada por ele como uma ingerência indevida, seja de um modo de pensar pré-crítico, ainda prenhe de resíduos escolásticos, seja do método científico erigido, pelo positivismo, em padrão do método filosófico:

Enquanto o movimento que surge com Kant, voltado contra resíduos escolásticos no pensamento moderno, coloca no lugar das definições verbais a concepção de conceitos a partir do processo em que eles são gerados, as ciências particulares insistem, em função da imperturbável segurança de seu modo de operar, na obrigação pré-critica de definir; nisso, os neopositivistas, para os quais o método científico é sinônimo de filosofia, coincidem e concordam com a escolástica. (Adorno, 1986, p. 176)

Adorno rejeita as definições tanto como procedimento operatório - "o ensaio exige mais que o procedimento por definições, interação dos seus conceitos no processo da experiência espiritual" -, quanto como ponto de partida da filosofia: "o ensaio, em contrapartida, assume em seu próprio proceder o impulso anti-sistemático e, sem cerimônias, introduz 'imediatamente' conceitos tais como os recebe e concebe" (Adorno, 1986, p. 176).

Descartado como momento inicial e como método, o procedimento de expor a partir de definições tampouco ressurge na decantação conceitual. Embora Adorno destaque que os conceitos, considerados como sedimentações, estão mediatizados pela história, pelo processo de socialização, pela 
linguagem, nem por isso ele adota a metodologia da análise significacional fenomenológica:

O ensaio parte dessas significações e, sendo ele mesmo essencialmente linguagem, leva-as avante; ele gostaria de ajudar a linguagem em sua relação com os conceitos, de tomá-los refletidamente tais como eles já se encontram inconscientemente denominados na linguagem. Isso é pressentido, na fenomenologia, pelo procedimento da análise significacional, só que aí a relação dos conceitos com a linguagem se converte em fetiche. $\mathrm{O}$ ensaio se posiciona tão ceticamente diante disso quanto diante da pretensão de definir. Sem apologia, assume a objeção de que é impossível saber acima de qualquer dúvida que idéias se deveria fazer dos conceitos. Pois percebe que exigir definições estritas contribui há muito tempo para eliminar, mediante a manipulação dos significados dos conceitos através de sua fixação, o elemento irritante e perigoso das coisas, que vive nos conceitos. (Adorno, 1986, p. 176)

\section{História e verdade}

O ponto de partida da teoria, segundo Adorno, não deve ser nem definições, nem o imediato, mas sim os conceitos estabelecidos da tradição filosófica. A matéria prima que cabe à filosofia trabalhar consiste no próprio pensamento, desdobrado em chave histórica. Afinal, "textos a serem interpretados e criticados constituem um apoio inapreciável para a objetividade do pensamento" (Adorno, 1980, p. 19).

$\mathrm{Na}$ abordagem da história da filosofia, Adorno adota um viés próprio. Rejeitando a concepção atomizada e estática dessa história, defende, em contraposição às posições que afirmam pensamentos e pontos de vista eternos ou atemporais, uma convergência da perspectiva histórica e do ponto de vista crítico:

Desde os enaltecidos pré-socráticos, os filósofos tradicionalmente transmitidos foram críticos. Xenófanes, a cuja escola remonta o conceito de ser, que hoje é voltado contra o conceito, queria desmitologizar as forças naturais. O fato de Platão hipostasiar o conceito em idéia foi percebido por Aristóteles. Na época moderna, Descartes mostrou que a escolástica dogmatizara a mera opinião. Leibniz foi o crítico do empirismo; Kant o de Leibniz e, ao mesmo tempo, de Hume; Hegel o de Kant, Marx o de Hegel. (...) Esses pensadores tinham na crítica a própria verdade. Somente ela, enquanto unidade do problema e de seus argumentos, e não a adoção de teses, estabeleceu aquilo que se pode considerar como a unidade produtiva da história da filosofia. Desenvolvendo uma tal crítica, mesmo os filósofos em cuja doutrina persistia o eterno e o intemporal obtiveram o cerne do seu tempo, sua localização histórica. (Adorno, 1964, p. 14-15)

Nesse tópico, na convergência de crítica e história, pode-se identificar novamente a presença e o nexo entre o momento especulativo e a busca de 
concreção. Mas cabe também observar que essa mediação, fiel ao espírito da dialética negativa, não implica o estabelecimento de nenhuma hierarquia ou ordem de precedência. Procura-se evitar o predomínio seja da perspectiva histórica seja da sistemática.

Assim, a preocupação com o ponto de vista histórico, a rejeição do apriorismo lógico, não acarreta o abandono ou a desaparição do sistemático. Ao contrário:

As intersecções e incongruências históricas que se dão entre os conceitos não podem ser atribuídas simplesmente à história, como se fossem algo não conceitual que nada tivesse que ver, como se sói dizer, com o sistemático, portanto, com as questões em torno da verdade. As mudanças históricas da filosofia, e esta é pelo menos uma mediação essencial entre o aspecto por assim dizer histórico e o aspecto por assim dizer objetivo, procedem antes em larga medida de questões objetivas ou sistemáticas. (Adorno, 1974, p. 44)

De outro lado, a atenção a questões objetivas ou sistemáticas não impede Adorno de recusar a ideia tradicional de verdade, ou melhor, a concepção que a compreende como uma busca de essências atemporais. O histórico, ele insiste, deve ser efetivamente incluído como momento essencial da verdade:

o ensaio não se deixa intimidar pelo depravado pensamento profundo de que verdade e história se contraponham irreconciliavelmente. Se a verdade tem, de fato, um núcleo temporal, então, o pleno conteúdo histórico se converte num momento integral dela; o "a posteriori" se torna concretamente um "a priori", como Fichte e seus seguidores o exigiram somente em termos gerais. (Adorno, 1986, p. 174)

O conceito inicial, do qual parte a reflexão em Adorno, consiste em algo já sedimentado historicamente como objeto. Trata-se, portanto, de determinações históricas e não de um constructum lógico. Por outro lado, enquanto conceito, tampouco é algo puramente factual, empírico. O procedimento de Adorno consiste, assim, em submeter esse conceito, ao mesmo tempo sistêmico e histórico, a um duplo movimento: à crítica e à concreção.

Esse procedimento efetiva-se pela mediação da "experiência espiritual", compreendida não como mecanismo puramente subjetivo que como tal pré-formaria os fatos, mas como resultante de um confronto com o heterônomo, de uma referência ao histórico:

A referência à experiência - e o ensaio lhe empresta tanta substância quanto a teoria tradicional às meras categorias - é uma referência a toda a história; a experiência apenas individual, com a qual tem início a consciência como aquilo que lhe 
é mais próximo, está ela mesma já mediada pela experiência mais abrangente da humanidade histórica [...] Por isso, o ensaio passa a rever e revidar o menosprezo pelo historicamente produzido como objeto da teoria. (Adorno, 1986, p. 174)

A crítica busca, com a mediação do especulativo, modificar a orientação da conceptualidade, redirecionando-a para o não-idêntico. O simples ato de ressaltar a universalidade do conceito acarreta a percepção de que o particular também habita, assim como é habitado, a universalidade. O conceito é, portanto, em si mesmo seu outro, já que está indissoluvelmente atado a este outro. No particular, por sua vez, o momento que se configura como indefinível por intermédio do conceito excede sua existência singular, ao ser colocado em relação com àquilo que não é ele mesmo. Assim mediado, tal momento torna-se o objeto preferencial de uma constelação conceitual.

Entretanto, para perceber a constelação na qual a "coisa" se encontra, para decifrar a história que o singular carrega em si como resultado de um desdobramento, para conhecer o processo nele acumulado, o pensamento não pode prescindir de um sujeito fortalecido. Somente esse se encontra habilitado - na medida em que concentra a espontaneidade e a concentração necessárias - a desenrolar a história sedimentada no objeto, pois somente pela experiência espiritual pode-se apreender a universalidade imanente do singular como objetiva.

MUSSE, Ricardo. Theodor Adorno: philisophy of content and critical model. Trans/ Form/Ação, São Paulo, v.32(2), 2009, p.135-145.

- ABSTRACT: Here it is aimed to highlight some personal characteristics of Theodor Adorno's philosophical exposure through his relation of mutual dependence amongst the concrete and the speculative. The denial of definitions, the search for constellations, the building of "critical models" become more intelligible when observed under the light of the concepts and the non-conceptual. Therefore, it is intended to better explain the relation between truth and history in Adorno's thinking.

- KEYWORDS: Theodor Adorno, critical theory, Marxism.

\section{Referências bibliográficas}

ADORNO, Theodor. Eingriffe. Neun kritische Modelle. Frankfurt am Main: Suhrkamp, 1964.

. "Parataxis". Em: ADORNO, Theodor. Notas de literatura. Rio de Janeiro: Tempo Brasileiro, 1973. 
ADORNO, Theodor. Philosophische Terminologie. Zur Einleitung, b.1-2, Herausgegeben von Rudolf zur Lippe. Frankfurt am Main: Suhrkamp, 1974.

. Stichworte. Frankfurt am Main: Suhrkamp, 1980.

. Negative Dialektik. Frankfurt am Main: Suhrkamp, 1982.

. "O ensaio como forma". Em: COHN, Gabriel. Theodor Adorno. São Paulo: Ática, 1986. 